\title{
Estado Novo: o fim das políticas regionais?
}

\author{
LUCIANO ARONNE DE ABREU*
}

\begin{abstract}
Resumo: Em geral, a História Republicana do Brasil divide-se em antes e depois da Era Vargas, sendo este período o marco divisório entre o Brasil arcaico, marcado pelo clientelismo e pelo poder das tradicionais oligarquias políticas regionais, e o Brasil moderno, onde vigoram o universalismo de procedimentos e o ideal de manutenção da ordem e da unidade nacional. Ao longo deste texto, porém, procuramos demonstrar que o Brasil é, na verdade, um país sincrético, como define Edson Nunes, onde o arcaico e o moderno mantém-se em constante interação, mesmo após as reformas de tipo universalista implementadas durante os anos Vargas. Durante este período, portanto, ainda que as políticas regionais tenham, de fato, sido limitadas em sua autonomia, novos canais de acesso e influência ao poder central permitiram às tradicionais oligarquias a manutenção de seu poder regional.
\end{abstract}

\begin{abstract}
Brazilian republican history is generally divided between before and after Vargas Era, landmark of the end of the "archaic Brazil", ruled by traditional oligarchies regionally based, and the "modern Brazil", characterized by the adoption of universal social proceedings and ideals of political order and national unity. Nevertheless, this paper aims to demonstrate that Brazil should rather be considered as a synchretic society, like defined by Edson Nunes. It means that archaism and modernity constantly interacted with each other, even though Vargas' government intended to put into operation some reforms to establish the universality of political-administrative procedures. During this time, the autonomy of regional politics was in fact restricted, but new channels of influence in federal government allowed traditional oligarchies to keep power in their political supporting basis.
\end{abstract}

Palavras-chave: Estado Novo. Política Regional. Interventorias.

Key words: Estado Novo. Regional politics. Interventorias.

\section{Algumas questões conceituais}

De um modo geral, a Era Vargas é vista por nossa historiografia como uma ruptura em relação à República Velha, que se caracterizava por um forte regionalismo e pelo predomínio político das oligarquias cafeicultoras. Nesse sentido, tomando-se a Re-

* Professor no Departamento de História da PUCRS. Doutor em História LatinoAmericana pela UNISINOS.

Estudos Ibero-Americanos. PUCRS, v. XXXIII, n. 1, p. 172-191, junho 2007 
volução de 30 como um momento privilegiado desse processo, construiu-se a partir dos anos 1960 uma interpretação dualista da sociedade brasileira, com raízes no interior do pensamento de esquerda, opondo basicamente os setores agrário-latifundista e capitalista urbano. ${ }^{1}$

No entanto, ao contrário desse dualismo, Bóris Fausto demonstrou que a revolução de 30 , ainda que expressasse a necessidade de reajustar as estruturas do país e pusesse fim à hegemonia política dos cafeicultores, não foi a expressão de uma oposição radical entre os interesses agrários e industriais, pois havia uma complementaridade básica entre esses setores. Além disso, diz ele,

vitoriosa a revolução, abre-se uma espécie de vazio de poder por força do colapso político da burguesia do café e da incapacidade das demais frações de classe para assumi-lo, em caráter exclusivo. O Estado de Compromisso é a resposta para essa situação. ${ }^{2}$

Nesse mesmo sentido, pode-se afirmar que a formação de um Estado de Compromisso não ocorreu apenas durante o chamado Governo Provisório, mas estendeu-se por toda a Era Vargas, sendo uma de suas principais marcas. Durante o Estado Novo, por exemplo, o governo contou com o apoio de diferentes segmentos da sociedade, tais como o Exército, as oligarquias estaduais, as classes produtoras, a Igreja e os integralistas. ${ }^{3}$ A esse respeito, inclusive, Eli Diniz chega a afirmar que a centralização e o fortalecimento do Executivo durante o Estado Novo podem ser concebidos como o "clímax de todo um processo político marcado por uma crise de poder" - que teria se iniciado em 1930 - "em que a incapacidade de qualquer dos grupos em confronto impor-se aos demais seria o traço dominante". 4 Sendo assim, uma das formas do regime acomodar e dar visibilidade a esses diferentes setores dominantes seria o estabelecimento de um complexo jogo de influências. Em conseqüência, conclui Diniz:

O controle do poder central sobre o processo decisório deve ser entendido num sentido relativo, na medida em que a consolidação das tendências coercitivas e centralizadoras que, a partir da mudança do regime político, passa a ser a tônica do reaparelhamento estatal, im-

1 FAUSTO, Bóris. A Revolução de 30 - historiografia e história. São Paulo: Brasiliense, 1994, 13를. ed., 12.

2 Ibid., p. 113.

3 CARONE, Edgar. O Estado Novo (1937-45). São Paulo: DIFEL, 1976, p. 257-261.

4 DINIZ, Eli. O Estado Novo: estrutura de poder e relações de classe. In: FAUSTO, Bóris (org.). História Geral da Civilização Brasileira - Brasil Republicano III. São Paulo: DIFEL, 1981, p. 84. 
plicaria não uma exclusão da influência, senão uma redefinição dos canais de acesso e influência, através das quais a interferência dos diferentes grupos se faria sentir a partir de então (...). ${ }^{5}$

Desse modo, se admitimos que o controle decisório do poder central durante o Estado Novo foi relativo, devemos igualmente admitir que os limites impostos às políticas e à autonomia regional também não foram plenos e, portanto, continuar a interpretar a Era Vargas a partir das clássicas ambigüidades entre o tradicional e o moderno, e o regional e o nacional não nos permite compreender esse período em toda a sua complexidade.

Por isso, concordamos com Edson Nunes ${ }^{6}$ quando ele define a sociedade brasileira como sincrética e, na tentativa de melhor compreender as relações e a estrutura política do Estado Novo, optamos por analisá-las sob uma nova perspectiva: exatamente a das políticas regionais e de seus novos canais de influência junto ao governo federal, como veremos adiante.

Foi durante a Era Vargas, segundo Nunes, que se buscou implantar no Brasil uma lógica capitalista moderna e internacionalizada, o que exigiu, além de uma modernização econômica, a criação de uma série de instituições que regulassem as relações entre o Estado e a sociedade, o que levou, em conseqüência, esta moderna ordem capitalista a penetrar em todas as esferas da vida social. Porém, deve-se ressaltar que essa modernização econômica e a criação das novas instituições não se dão de uma hora para outra, nem chegam a alterar o conjunto da sociedade da mesma forma e nas mesmas proporções. Portanto, conclui Nunes, a implantação da nova ordem não chegou a eliminar completamente a antiga, sendo que esta interação entre a velha e a nova ordens é que veio a configurar o caráter sincrético de nossa sociedade.

Contudo, a simples constatação desse fato não é suficiente: é preciso perceber-se a sistemática dessa interação - de que forma ela ocorre? Em resposta a esta questão, Edson Nunes identifica quatro principais gramáticas que, apesar de estarem baseadas em princípios antagônicos, são empiricamente compatíveis e, a partir dos anos Vargas, passaram a pautar as relações entre o Estado e a sociedade no Brasil: universalismo de procedimentos, clientelismo, insulamento burocrático e corporativismo.

Historicamente, a construção de uma autoridade racional e territorialmente universal foi um fator-chave para o desenvolvi-

5 Ibid., p. 85.

6 NUNES, Edson. A gramática política do Brasil - clientelismo e insulamento burocrático. Rio de Janeiro: Jorge Zahar, 1997. 
mento dos estados capitalistas modernos, erodindo o poder local e levando à concentração do poder nas mãos do Estado. Desse modo, talvez a principal característica desse novo poder público seja a de ser regulado por normas e instituições baseadas no universalismo de procedimentos, ou seja, "normas que podem ser formalmente utilizadas por todos os indivíduos da polity ou a eles aplicadas". 7 Além disso, deve-se ressaltar que em contextos universalistas as relações sociais baseiam-se principalmente no individualismo e no impersonalismo e as trocas que ocorrem são específicas, não gerando expectativas de ganhos futuros.

Entretanto, alerta Nunes, estas mudanças estão diretamente associadas a uma parte restrita do globo, representada pelos Estados Unidos e pelo noroeste da Europa, onde houve uma combinação própria de condições políticas, econômicas e sociais que se interconectam. Desse modo, conclui o autor, o capitalismo deve ser entendido como um "pacote de condições e relações entre variáveis no contexto da produção capitalista", devendo-se falar, portanto, em "variantes do capitalismo", 8 que podem ter condições similares e ser, ao mesmo tempo, diferentes uma da outra. Este é o caso, por exemplo, do Brasil de Vargas, onde estes princípios universalistas do capitalismo moderno vão se combinar com aqueles da antiga ordem clientelista: é o sincretismo brasileiro.

Quanto ao clientelismo, este pode ser definido como "um tipo de relação social marcado por contato pessoal entre patrons e camponeses. Os camponeses, isto é, os clientes, encontram-se em posição de subordinação, dado que não possuem a terra". ${ }^{9}$ Originalmente, como se pode notar, o clientelismo está associado às sociedades rurais, nas quais a família se constitui em uma unidade básica de produção e de consumo, havendo uma certa confusão entre os mundos econômico e social. No caso do Brasil, mesmo em contextos urbanos onde se implantou um capitalismo moderno, os laços pessoais e familiares mantém-se como um componente importante de nossas relações sociais e econômicas. Em sociedades clientelistas, diz Nunes, ao contrário do univesalismo de procedimentos, as trocas são generalizadas e pessoais, incluindo promessas e expectativas de retornos futuros. Nesse sentido, diz ele:

O clientelismo repousa num conjunto de redes personalistas que se estendem aos partidos políticos, burocracias e cliques. Estas redes envolvem uma pirâmide de relações que atravessam a sociedade de

Ibid., p. 23.

8 Ibid., p. 25.

9 Ibid., p. 27. 
alto a baixo. As elites políticas nacionais contam com uma complexa rede de corretagem política que vai dos altos escalões até as localidades. Os recursos materiais do Estado desempenham um papel crucial na operação do sistema; os partidos políticos - isto é, aqueles que apóiam o governo - têm acesso a inúmeros privilégios através do aparelho do Estado. ${ }^{10}$

Em contraponto a essas tradicionais práticas clientelistas, no afã de inserir o Brasil na citada lógica capitalista moderna, o Estado varguista utilizou-se também do chamado insulamento burocrático, com a criação de novas instituições que deveriam se constituir em verdadeiras ilhas de racionalidade e de especialização técnicas, "que não seriam receptivas a demandas fisiológicas e clientelistas dos partidos políticos". 11 Talvez o melhor exemplo de instituição insulada criada durante o Estado Novo seja o do Departamento Administrativo do Serviço Público (DASP), que tinha por objetivo reformar a administração pública com base nos critérios de racionalidade, economia e eficiência.

Entretanto, mesmo no caso do DASP, deve-se ressaltar que há variações no grau de insulamento e que, além disso, nem todas as instituições insuladas permanecerão assim com o passar do tempo. Portanto, afirma Edson Nunes, ao contrário da retórica dos seus patrocinadores e dos objetivos pretendidos pelo Estado, "o insulamento burocrático não é de forma nenhuma um processo técnico e apolítico". ${ }^{12}$

A respeito do corporativismo, pode-se dizer que esta gramática também representou, durante o Estado Novo, a busca de uma racionalidade e de uma organização contrárias ao clientelismo. Nesse sentido, o corporativismo constituiu-se em um instrumento de incorporação e controle dos indivíduos e dos diferentes grupos sociais pelo Estado, impedindo seu desenvolvimento autônomo e procurando evitar conflitos. Porém, ainda que baseado em normas gerais escritas, o corporativismo não deve ser confundido com o universalismo de procedimentos, pois suas normas se referem a setores específicos da sociedade, regulam a organização interna desse grupo e o subordinam diretamente ao Estado.

Nesta perspectiva, a partir destas gramáticas e da idéia de uma sociedade sincrética, pode-se dizer que a Era Vargas não representou uma total ruptura com os princípios políticos da República Velha, nem o Estado Novo rompeu plenamente com as carac-

$10 \quad$ Ibid., p. 32.

11 Ibid., p. 32.

12 Ibid., p. 35. 
terísticas anteriores a 1937. Desse modo, como já referimos, procuramos compreender o Estado Novo não em uma perspectiva linear e homogênea, como se a política de nacionalização e centralização do regime representassem, de fato, o fim das políticas regionais e o início de um Brasil totalmente novo e moderno, mas a partir exatamente das políticas regionais e de suas complexas relações com o governo federal.

A partir dos casos da interventoria gaúcha e do Conselho Administrativo do Estado do Rio Grande do Sul (CAE) buscamos demonstrar que, primeiro, o universalismo de procedimentos e o clientelismo conviviam de forma harmônica tanto na estruturação destas novas instituições como em suas práticas políticas e administrativas; segundo, o controle que o governo federal exercia sobre as políticas regionais através da interventoria e do CAE não deve ser visto em sentido pleno, na medida em que estas instituições também deviam negociar e compor com as elites estaduais a fim de garantir a ordem e a legitimidade do próprio regime.

Antes de proceder-se à análise destas questões, porém, devese esclarecer que este trabalho vem a somar-se aos estudos ainda incipientes de história política regional sobre o Estado Novo que, até a década de 1990,13 praticamente inexistiam. Aliás, como demonstraram René Gertz ${ }^{14}$ e Maria Helena Capelato ${ }^{15}$ em suas pesquisas sobre a historiografia desse período, mesmo em nível nacional os estudos sobre o Estado Novo foram escassos durante os anos 1970, ganhando impulso apenas na década seguinte. ${ }^{16}$ Por

13 A partir dos anos 1990 encontramos um grande número de estudos de história regional sobre o Estado Novo, sendo que muitos deles se referem às temáticas da nacionalização do ensino e da repressão aos imigrantes. Dentre os que abordam especificamente a questão política, destacamos os seguintes: COLUSSI, Eliane. Estado Novo e Municipalismo gaúcho. Passo Fundo: UPF, 1996. AMARAL, Sandra Maria do. Elite política e relações de poder: o caso de Ijuí - 1938-45. Passo Fundo: UPF, 2000 (dissertação de mestrado); CAVALHEIRO, Maria Heloísa. Relações de poder no Estado Novo: uma permanência sui generis - o caso Albino Hillebrand em Carazinho - RS. Passo Fundo: UPF, 2003 (dissertação de mestrado.

14 GERTZ, René. Estado Novo: um inventário historiográfico. In: SILVA, José Luiz Werneck da (org.). O feixe e o prisma - uma revisão do Estado Novo. Rio de Janeiro: Jorge Zahar, 1991.

15 CAPELATO, Maria Helena. Estado Novo: novas histórias. In: FREITAS, Marcos César (org.). Historiografia brasileira em perspectiva. São Paulo: Contexto, 2001.

16 Na opinião de Capelato, a pouca dedicação dos historiadores ao período estadonovista, até a década de 1970, se devia às concepções então vigentes acerca do fazer história: por um lado, exigia-se um distanciamento maior entre o tempo do historiador e o do objeto estudado; por outro, a história política era criticada por ser mais factual, privilegiando-se os estudos de sociedade e cultura, de cunho mais estrutural. Já nos anos 1980, novos paradigmas passaram a pautar a história política, valorizandose os estudos do tempo presente. Além disso, em um contexto de abertura democrá- 
fim, sendo este um estudo de história regional, deve-se ainda esclarecer que

El regionalismo se define aquí como un comportamiento político caracterizado, por un lado, por la aceptación de la existencia de una unidad política mayor, pero por otra parte, por la búsqueda de favoritismo y autonomía en las decisiones de la unidad mayor en las políticas económicas y sociales, aun corriendo el riesgo de poner em jaque la legitimidad del régimen político imperante. Por lo tanto, el énfasis no recae sobre las peculiaridades regionales per se (por ejemplo, el folclor, vestimenta y lenguaje), sino sobre aquellos factores que pueden demostrarse que afectan las relaciones políticas, económicas y sociales de la región com otras regiones y com la unidad gubernamental mayor, generalmente el Estado-nación. ${ }^{17}$

Ou seja, ao enfatizarmos questões de política regional não pretendemos negar a existência de uma unidade política maior ou de um projeto político centralizador e nacionalista por parte do Estado Novo, mas identificar e compreender a busca, por parte das elites regionais, de possíveis espaços de autonomia em suas decisões políticas e administrativas (através da interventoria e do CAE), e os modos de relações das regiões com o governo federal.

\section{Algumas questões de política regional no Rio Grande do Sul}

A partir de 1937, sob o argumento de manter a ordem, combater o comunismo e garantir a unidade nacional, o governo federal decretou o fechamento dos órgãos legislativos e dos partidos políticos, supostamente "eliminando os intermediários entre o governo e o povo", como dizia Getúlio Vargas. Naturalmente, na esteira destas mudanças, o poder político dos estados e das oligarquias regionais também sofreria uma série de restrições com o processo de centralização do poder implantado em nível federal. A respeito desses acontecimentos, Eliana Dutra diz que

Na esteira do desencanto com as vantagens da vida partidária e com a eliminação da 'competição de interesses', está posta a crítica ao regionalismo, como sendo um empecilho à coesão nacional. Afinal, o regionalismo é a imagem insuportável da pátria partida e um entrave à construção da imagem de uma pátria una e da sua consciência

tica no país, os historiadores voltaram ao Estado Novo como forma de compreender as raízes de nossa cultura política autoritária (ibid., p. 188).

17 LOVE, Joseph. Una aproximacción al regionalismo. Barranquilla: Colombia: Universidade del Norte, 1993, p. 4. 
enquanto tal. A contrapartida da negação regional é a afirmação da integridade do corpo pátrio e, contra ela, o regionalismo é um mal e a política partidária, considerada sua expressão, também o é. ${ }^{18}$

Nesse contexto, a necessidade de uma maior integração nacional era admitida até mesmo por setores ligados às próprias oligarquias estaduais que, como vimos, apoiaram a implantação do Estado Novo e integraram o Estado de Compromisso que se formou em torno deste regime. Entretanto, não se deve confundir o combate ao regionalismo com o fim das políticas regionais, nem o fechamento dos partidos políticos com o fim da política de partidos, ao menos no caso gaúcho.

Sobre as controvérsias surgidas em torno à questão do regionalismo, Fernando Callage, em texto publicado no jornal Correio do Povo, disse que "para amar o Brasil e ter um sentimento de unidade nacional tem que primeiramente adorar o seu chão sagrado, para depois sim, adorar o grande todo". Mais adiante, porém, admitiu que se devia combater

a situação política de rivalidades estadualistas, rivalidades que culminam, muitas vezes, em revoluções e levam a desconhecer o próprio valor e o esforço de seus irmãos brasileiros.

Não se deve confundir o sentimento regional inerente à cada região do país com esse mesquinho localismo político que vive de disputas pelos cargos federais, gerando ódios inconfessos e lutas sangrentas que põe em cheque a unidade nacional. Um é salutar à vida da nacionalidade; outro oferece um perigo à própria vitalidade do país. ${ }^{19}$

Em outras palavras, pode-se dizer que Callage não critica o sentimento regional, considerado salutar à nacionalidade, mas o localismo político que, para ele, constitui-se em um perigo à vitalidade do país. Na prática, porém, essa distinção talvez não seja tão nítida e, ao contrário, essas questões possam até mesmo confundirse ou serem confundidas pelos agentes políticos na defesa que fazem dos interesses regionais e em suas disputas pelo poder. Exemplar nesse sentido foi a observação de Protásio Vargas sobre as condições políticas do Rio Grande do Sul logo após o golpe de 10 de novembro, quando afirmou que "o que notei aqui entre as excorrentes partidárias é que há uma recíproca falta de confiança e por isso algo subterrâneo, trabalhando o espírito partidário. Não há partidos políticos, porém existe política de partidos”. ${ }^{20}$

18 DUTRA, Eliana. O ardil totalitário - imaginário político no Brasil dos anos 30. Rio de Janeiro/Belo Horizonte: UFRJ/UFMG, 1997, p. 178-9.

19 Correio do Povo, Porto Alegre, 5 de abril de 1938, p. 5.

20 CPDOC/FGV. Arquivo GV 38.04.26/2 XXIX - 62. 
Em nossa opinião, as origens dessa falta de confiança constatada por Protásio, ao menos as mais imediatas, podem ser encontradas nos episódios ocorridos em nível nacional e regional a partir da revolução paulista de 1932, quando os gaúchos romperam sua unidade em torno da liderança de Getúlio Vargas e voltaram a dividir-se em dois blocos políticos antagônicos ou, como diz Sandra Pesavento, em duas alas: a "ala regional" e a "ala nacional" da oligarquia rio-grandense: 21 a primeira, ligada ao Partido Libertador (PL) e aos setores borgistas do Partido Republicano Riograndense (PRR), que defendia o fim do Governo Provisório e a volta do país à ordem constitucional; a segunda, de tendência mais autoritária, liderada pelo Governador Flores da Cunha, que defendia a manutenção do poder discricionário de Vargas como forma de manter a ordem e a unidade do país.

Com a derrota dos revolucionários de 1932, coube aos integrantes da Frente Única Gaúcha (ala regional) o exílio, enquanto à ala nacional ficou reservado o controle do governo estadual e um lugar de destaque na base de apoio parlamentar a Getúlio Vargas, criando-se para isso um novo partido político - o Partido Republicano Liberal (PRL). Desse modo, segundo Derocina Campos, a partir da atuação do PRL o Rio Grande do Sul "conseguiu finalmente uma posição influente sobre o governo provisório, pois ajudando a combater os revolucionários, a nível (sic) estadual e federal, tornava-se um aliado mais que necessário", 22 tornando-se o PRL uma espécie de ponto de equilíbrio da política nacional e regional.

Nas eleições de 1933, para que se tenha uma idéia mais clara deste novo quadro político, o PRL obteve 132.056 votos $(77,92 \%)$ contra 34.430 votos $(22,08 \%)$ da FUG. Ou seja, estes resultados eleitorais não deixam dúvidas acerca do perfeito funcionamento desta nova estrutura partidária e de poder organizada por Flores da Cunha no Rio Grande do Sul.

Num primeiro momento, segundo Hélgio Trindade, esta vitória de Flores representou, de forma concreta, "um acréscimo de poder pessoal e, na medida em que era, também, Interventor, os resultados reforçam a posição de seu governo como força estadual autônoma". ${ }^{23}$ No momento seguinte, entretanto, foi justamente

21 PESAVENTO, Sandra. RS: a economia e o poder nos anos 30. Porto Alegre: Mercado Aberto, 1980, p. 143.

22 CAMPOS, Derocina Alves. Federalismo versus centralização: a década de 30 no Rio Grande do Sul. Rio Grande: FURG, 2001, p. 25.

23 TRINDADE, Hélgio. Revolução de 30: partidos e imprensa partidária no RS (1928-37). Porto Alegre: LPM, 1980, p. 162. 
este caráter autônomo do poder de Flores da Cunha e sua crescente influência sobre a política nacional que levaram ao seu enfrentamento político com Getúlio Vargas.

Tais relações começaram a modificar-se, sobretudo, a partir de 1934, em um contexto de maior abertura democrática, com a anistia concedida aos exilados políticos; e, em 1935, com a ocorrência da chamada Intentona Comunista em Natal, Recife e no Rio de Janeiro. Por um lado, no Rio Grande do Sul, o retorno à atividade política de lideranças como Borges de Medeiros e Raul Pilla levou ao fortalecimento da oposição da FUG aos governos de Flores da Cunha e Getúlio Vargas. Por outro lado, tanto a FUG quanto o PRL apoiavam o governo federal em suas ações de repressão ao comunismo, mas mostravam-se contrários à aplicação da Lei de Segurança Nacional no estado, que diziam não ter sido ameaçado em sua ordem interna pelo "perigo comunista".

Frente a estes novos acontecimentos, pode-se perceber gradativamente um deslocamento do ponto de equilíbrio do jogo político regional e nacional do PRL para a FUG. Para Flores da Cunha, conquistar o apoio da FUG significaria unir novamente a oligarquia gaúcha em torno de sua liderança pessoal e fortalecer-se diante do governo federal; para Getúlio Vargas, seria um meio de limitar o caráter autonomista do poder de Flores e fortalecer sua política autoritária e centralizadora, que começava a ser esboçada nesse momento. Nessas circunstâncias, o ano de 1936 foi marcado sucessivamente pela celebração de um "modus vivendi" regional entre a FUG e o PRL e, a seguir, pelo seu rompimento e pela adesão da FUG à política varguista.

No Rio Grande do Sul, pode-se dizer que o "modus vivendi" constituiu-se essencialmente em "uma forma encontrada para a boa convivência entre os partidos políticos gaúchos", ${ }^{24}$ ainda que cada um deles mantivesse sua autonomia e distinção e que suas antigas divergências não tivessem sido totalmente superadas. Aliás, as próprias expectativas desses partidos com o acordo eram diversas. Para a FUG, este talvez fosse o caminho possível para fortalecer-se politicamente e retornar ao poder estadual, do qual estava afastada desde 1932. Para Flores da Cunha e o PRL, o que se buscava era a consolidação do seu poder regional e, a partir disso, a ampliação de sua influência política em nível nacional. Em conseqüência, pode-se dizer que o ponto mais forte de atração entre esses partidos foi a noção comum de que nenhum deles, isoladamente, tinha força política suficiente para atingir seus objetivos: 
exercer de forma hegemônica o poder regional ou influir de forma decisiva na política nacional.

Nessas condições, a fórmula acertada para o "modus vivendi" mostrou-se contraditória e incapaz de obter a conciliação desses diferentes interesses das elites políticas gaúchas, posto que a chamada "fórmula Pilla", ${ }^{25}$ como ficou conhecida, estabelecia a formação de um regime em moldes parlamentares no Rio Grande do Sul, com a nomeação de dois integrantes da FUG para o secretariado de Flores da Cunha: Lindolfo Collor (PRR) para a Secretaria da Agricultura e Raul Pilla (PL) para a Secretaria da Fazenda.

Este regime de gabinete, entretanto, ao contrário de suas propaladas intenções, constituiu-se em um novo foco de disputas entre as alas regional e nacional da oligarquia gaúcha, opondo exatamente a base parlamentar da FUG e o poder Executivo, exercido de forma autoritária por Flores da Cunha. A esse respeito, por exemplo, Loureiro da Silva avaliou que "o acordo foi recebido friamente pelo nosso partido (PRL) e, em certos meios, sobretudo nas classes conservadoras, com uma pontinha de ironia". ${ }^{26} \mathrm{~A}$ seguir, em previsão certeira, Loureiro da Silva afirmou: "Prevejo lutas atrozes para a nossa terra, na sucessão presidencial. Ilude-se quem pensar em uma unanimidade do Rio Grande neste ponto". ${ }^{27}$

De parte da FUG, este acordo também foi avaliado com ceticismo por líderes como João Neves da Fontoura, Maurício Cardoso e Batista Luzardo, que defendiam a necessidade de estender-se este "modus vivendi" ao plano nacional, pois, segundo eles, a origem da divisão política regional ligava-se à revolução paulista de 1932 e, em conseqüência disso, as duas alas da elite política gaúcha relacionavam-se de maneiras opostas com o governo federal: o PRL integrava sua base de apoio, enquanto a FUG pertencia à oposição parlamentar.

Tais disputas podem ser ilustradas, no Rio Grande do Sul, por dois episódios significativos, um ocorrido em maio e outro em outubro de 1936. No primeiro caso, a bancada frente-unista na Assembléia Legislativa rejeitou um projeto do Executivo de criação

25 A “fórmula Pilla" pode ser resumida essencialmente nos seguintes pressupostos: a) o Governador deverá nomear um Presidente do Secretariado, que irá indicar os demais secretários de Estado; b) o secretariado, liderado por seu Presidente, deverá comparecer perante a Assembléia Legislativa para esclarecer seus projetos de governo; c) os desentendimentos entre o Governador e seus secretários serão submetidos à resolução do gabinete; d) a indicação dos secretários de Estado será feita pelas direções dos partidos coligados.

26 CPDOC/FGV. Arquivo GV 36.01.28/2 XXI - 29b.

27 Ibid. 
de um corpo auxiliar da Brigada Militar, destinado a fazer o policiamento do porto da capital. ${ }^{28}$ No segundo caso, a disputa se refere à eleição para a mesa diretora da Assembléia, quando a bancada parlamentar da Frente Única elegeu o deputado Alexandre Rosa para a vice-presidência do parlamento gaúcho, contrariando a orientação de Flores da Cunha, que apoiava o deputado classista A. J. Renner. ${ }^{29}$

Estes conflitos, em nossa opinião, são um reflexo direto daquelas diferentes expectativas a que nos referimos que os partidos políticos gaúchos possuíam quando da celebração do "modus vivendi". Sob a ótica de Flores da Cunha, por exemplo, a Frente Única deveria oferecer-lhe como contrapartida às duas secretarias de governo que ocupava a fidelidade de sua base parlamentar aos interesses do Executivo, o que reforçaria sua liderança pessoal e seu poder político regional. Para a Frente Única, ao contrário, sua pretensão era não só integrar mas, de fato, poder participar das decisões de um governo que, organizado em moldes parlamentares, deveria pressupor a autonomia do Legislativo e não sua total submissão à liderança pessoal do Governador.

No plano nacional, tal como previra Loureiro da Silva, estes conflitos políticos regionais refletiram-se nos debates e alianças políticas celebradas com vistas à eleição presidencial. Isso porque a Frente Única, ao ver suas expectativas de poder regional frustradas pelo autoritarismo de Flores da Cunha, foi-se afastando cada vez mais de sua liderança e buscando celebrar um acordo de união nacional com o Presidente Getúlio Vargas, o que ia de encontro às pretensões de poder floristas. Além disso, observou-se também neste momento um processo de dissidência no próprio PRL, liderado por Benjamin Vargas e Loureiro da Silva, que denunciavam as arbitrariedades e ameaças cometidas pelo Governador e igualmente aproximavam-se do governo federal. Após a eleição de Alexandre Rosa para a vice-presidência da Assembléia, por exemplo, Loureiro denunciou que "chegam a cada passo, às nossas casas, nas ruas por onde passamos, avisos com as mais estranhas advertências, como este: 'os senhores serão chacinados, serão mortos'". 30

Nessas condições, tornou-se inevitável o rompimento definitivo do "modus vivendi" regional e, em nível nacional, que a Frente Única e os setores floristas do PRL apoiassem candidatos diferentes à sucessão presidencial. De um lado, os frentistas e dissi-

28 Correio do Povo, 13 de maio de 1936, p. 11.

29 PESAVENTO, op. cit., p. 168.

30 GRANDI, Celito. Loureiro da Silva - o Charrua. Porto Alegre: Literalis, 2002, p. 76. 
dentes liberais tenderam a apoiar a candidatura de José Américo de Almeida, ainda que insistissem em negociações que pudessem indicar um candidato de consenso à presidência do país, o que se mostrou cada vez mais inviável. De outro lado, reagindo à perda de seu poder político pessoal, Flores da Cunha ampliou suas ações repressivas no Rio Grande e tentou recompor a antiga política dos estados, apoiando a candidatura de Armando de Sales Oliveira (SP) e propondo um pacto autonomista aos governadores Juracy Magalhães, da Bahia, e Carlos de Lima Cavalcanti, de Pernambuco. Entretanto, contrariando suas expectativas, o Governador baiano respondeu-lhe que "o verdadeiro patriotismo impõe o dever de um entendimento entre as maiores forças políticas nacionais, na busca de uma solução que atenda aos incontestáveis anseios de paz de toda a opinião brasileira", concluindo ainda que não encara a possibilidade de uma luta armada, "porque as revoltas de consciência contra as más causas, ainda contra as piores, não azedam um coração desinteressado". 31

Em conseqüência desses acontecimentos, enfraquecido e isolado no poder regional pelo rompimento do "modus vivendi" e sem obter o esperado apoio de paulistas, pernambucanos e baianos em suas pretensões políticas nacionais, restou a Flores da $\mathrm{Cu}$ nha somente recorrer à força militar. Com isso, deu aos seus opositores o argumento de que precisavam para solicitar a intervenção federal no Rio Grande do Sul, ${ }^{32}$ o que ocorreu de forma plena no mês de outubro de 1937, quando Flores viu-se obrigado a renunciar ao seu mandato e exilar-se no Uruguai, iniciando-se o Estado Novo em terras gaúchas antes mesmo do 10 de novembro.

\section{A política regional gaúcha no Estado Novo}

Por um lado, como vimos, o rompimento do "modus vivendi" gaúcho e o apoio da FUG a Getúlio Vargas foram fatores decisivos para a queda de Flores da Cunha e a eliminação do último foco de resistência à implantação do Estado Novo e à centralização do poder político pelo governo federal. Por outro lado, porém, como havia constatado Protásio Vargas, o Rio Grande do Sul manteve-se dividido politicamente e, portanto, ainda que o estado ti-

31 CPDOC/FGV. Arquivo FC tp 37.03.06 doc. 10.

32 Correio do Povo, 29 de abril de 1937, p. 1. 
vesse seus interesses econômicos subordinados aos nacionais ${ }^{33} \mathrm{e}$ passasse a ser governado por um Interventor Federal, em termos ideológicos os gaúchos jamais forneceram ao Estado Novo uma base de apoio forte e homogênea. ${ }^{34}$

Isso porque, mesmo com o fechamento do regime e dos partidos políticos, as linhas básicas das correntes políticas gaúchas seriam mantidas durante o Estado Novo, "organizadas em torno do governo Vargas ou em oposição a ele"35 (FUG e PRL). Nesse sentido, segundo Carone, "o caso gaúcho é sui generis, pois é o único estado onde as oposições nunca se enfraquecem e sempre se rearticulam". 36

Nessas circunstâncias, pode-se dizer que a manutenção da ordem interna no Rio Grande do Sul e sua integração à unidade nacional do Estado Novo foi uma tarefa das mais complexas a ser desempenhada por seus interventores, que deveriam também conciliar os interesses e as pretensões de poder dessas diferentes alas da oligarquia regional, constituindo-se em importantes elos de ligação entre os planos nacional e regional. Aliás, sobre o papel dos interventores, deve-se ressaltar que estes representavam uma forma de subordinação dos estados ao governo federal, mas, ao mesmo tempo, eram envolvidos pelas oligarquias estaduais e defendiam seus interesses, pois, como diz Carone, "apesar da relativa independência, sua política não se livra das pressões existentes". 37 Nesse mesmo sentido, Campelo de Souza afirma que

As interventorias situavam-se (...) a meio caminho entre a identidade e a independência face aos grupos dominantes estaduais. O elemento novo, contudo, que lhe confere caráter de inovação institucional, é o fato de haver sido implantado como um sistema, em todo o país, como um instrumento de controle e uma cunha do poder central em cada estado. ${ }^{38}$

Tendo-se em vista as citadas características sui generis da política rio-grandense, pode-se dizer que a interventoria gaúcha se constitui em uma importante referência de como os interventores,

33 RIOS, Angélica de Medeiros. Ser ou não ser italiano - descendentes de imigrantes em Santa Maria durante o Estado Novo. Porto Alegre: PUCRS, 2001 (dissertação de mestrado), p. 51.

34 Ibid. p. 54.

35 KONRAD, Gláucia. A política cultural do Estado Novo no Rio Grande do Sul - imposição e resistência. Porto Alegre: PUCRS, 1994, p. 108.

36 CARONE, Edgar. O Estado Novo (1937-45). São Paulo: DIFEL, 1976, p. 145.

37 Ibid. p. 146.

38 CAMPELO DE SOUZA, Maria do Carmo. Estado e partidos políticos no Brasil (193064). São Paulo: Alfa-Ômega, 1976, p. 88. 
em suas ações de governo, de fato situavam-se a meio caminho entre a identidade e a independência dos grupos regionais e, às vezes, do próprio governo federal.

No caso de Daltro Filho, por exemplo, que exerceu a interventoria gaúcha entre outubro de 1937 e janeiro de 1938, este tinha plena consciência da importância e da dificuldade de se manter a ordem pública e o equilíbrio político interno no Rio Grande do Sul, a fim de garantir a estabilidade do seu governo e do próprio Estado Novo. Sobre essas dificuldades, Protásio Vargas alertava que a "máquina florista" ainda estava de pé no estado e, portanto, recomendava: "convém não hostilizar elementos liberais floristas, procurando ao contrário atraí-los e absorvê-los", 39 o que será levado a efeito por Daltro. Além desta, talvez a maior dificuldade enfrentada por Daltro Filho tenha sido a falta de lideranças políticas suficientes para colocar à frente das administrações municipais, "necessitando cooptar pessoas de partidos opositores a Vargas antes de 1937". ${ }^{40}$

Nesse sentido, pode-se dizer que a simples intervenção federal no Rio Grande do Sul não seria suficiente para garantir a ordem política do Estado Novo. Por este motivo, ao compor seu secretariado de governo, Daltro Filho preocupou-se em dividi-lo entre as diferentes alas da oligarquia regional, como se pode perceber a seguir: Secretário do Interior: Maurício Cardoso (PRR); Secretário da Fazenda: Oscar Carneiro da Fontoura (PL); Secretário da Agricultura: Viriato Dutra (PRL); Secretário da Educação: Coelho de Souza (PRL); Secretário de Obras Públicas: Walter Jobim (PL); Prefeito de Porto Alegre: Loureiro da Silva (PRL). Com esta mesma disposição agiu o interventor gaúcho ao nomear uma Comissão Mista para indicar os nomes dos novos prefeitos municipais, de acordo com os seguintes critérios:

Estipula-se sobre o provimento das prefeituras vagas ou a vagarem em virtude das deliberações ulteriores do governo do estado: as prefeituras que vagarem e cujos titulares pertençam ao Partido Republicano Liberal (de Flores da Cunha) serão providas por elementos pertencentes à dissidência liberal, devendo, porém, o candidato ser indicado em harmonia com a Frente Única. Far-se-á exceção para casos especiais, como, entre outros, aqueles em que a maioria eleitoral da Frente Única for manifesta. Quanto às subprefeituras dos municípios em referência, deverão ser preenchidas de acordo com os índices eleitorais dos partidos coligados, reservando-se preferente-

39 CPDOC/FGV. Arquivo GV 37.10.01 XXVII - 37c.

40 KONRAD, op. cit., p. 120. 
mente aos elementos da Frente Única os distritos em que a mesma dispõe de maioria eleitoral (...). ${ }^{41}$

Ao final dos trabalhos dessa Comissão, de um total de 85 municípios existentes no Rio Grande do Sul em 1937, 36 permaneceram com os mesmos prefeitos, 28 passaram a ter um novo prefeito e, em 21 casos, seria feito um estudo mais meticuloso da situação, que seria posteriormente definida.

Por um lado, pode-se dizer que estas ações do interventor e da Comissão Mista representaram o ponto de equilíbrio possível das diferentes alas da oligarquia regional entre si e com o novo regime que, desta forma, aproximava-se e cooptava o apoio das elites dominantes estaduais. Por outro lado, estas mesmas ações marcaram uma certa independência do interventor em relação a estas oligarquias, que tiveram o exercício e a amplitude de seu poder restringidos e subordinados diretamente ao interventor.

Em algumas situações, porém, as tradicionais divergências entre estes grupos políticos regionais manifestaram-se de forma mais veemente, chegando a ameaçar a manutenção da ordem e do equilíbrio político pretendidos pelo interventor. A esse respeito, pode-se citar como exemplo um episódio ocorrido no município de Santa Rosa, onde houve uma certa resistência da comunidade local às decisões da Comissão Mista e/ou do interventor.

O município de Santa Rosa foi um daqueles 36 casos em que a Comissão Mista manteve o prefeito que havia sido eleito em 1935 - Oscar Germani (PRL) - o que desagradou aos integrantes da FUG, que reivindicavam o poder local. Diante das pressões da comunidade, Germani renunciou à prefeitura em 25 de fevereiro de 1938, sendo substituído interinamente por Alfredo Leandro Carlson que, por sua vez, foi substituído poucos meses depois pelo capitão Pautílho Palhares, da Brigada Militar.

Entretanto, descontentes com esta atitude do interventor, setores da elite municipal - comerciantes, industrialistas e agricultores - reivindicaram diretamente ao Presidente Getúlio Vargas que intercedesse "junto ilustre interventor Coronel Cordeiro de Farias no sentido de ser efetivado cargo de prefeito deste município o cidadão Alfredo Leandro Carlson, o qual com grande devotamento vem exercendo interinamente dito cargo". 42 De mesma forma, o próprio prefeito interino dirigiu-se a Vargas solicitando sua manutenção na prefeitura municipal, no que não obteve sucesso.

41 CARONE, op. cit., p. 153-54.

42 Arquivo Nacional. Fundo Gabinete Civil da Presidência da República. Caixa 100. Pacote Governo Federal - RS. 
Pode-se citar, ainda, um outro episódio ocorrido no município de Uruguaiana que, igualmente, pode ser visto como um exemplo de divergência política entre as elites regionais e, sobretudo, de resistência às decisões e ao poder do interventor. Tal como em Santa Rosa, Flodoardo Silva também foi mantido pela Comissão Mista no cargo de prefeito municipal, devido à sua afinação com o discurso estadonovista e, além disso, por sua "amizade pessoal com Vargas e Aranha, seu empenho no afastamento de Flores da Cunha e a ligação crescente como João Batista Luzardo". ${ }^{43}$ Ainda assim, Flodoardo renunciou ao seu cargo em 7 de março de 1939, o que pode ser explicado pelo teor desta carta que enviou ao então interventor gaúcho Cordeiro de Farias (fev/38 set/43):

O Presidente da República centraliza, em sua pessoa, toda a amplitude da autoridade, e transmite-a aos seus representantes estaduais, os interventores. Estes, para que não haja quebra de uniformidade no estatuto estabelecido e na salutar aplicação das normas administrativas, guardadas as devidas proporções, transmite, assim, a mesma autoridade centralizadora aos seus representantes diretos nos municípios, os prefeitos, que são os orientadores da vida municipal. Entretanto, não é o que está acontecendo no Rio Grande do Sul, muito francamente afirmo, mas com o acatamento e a estima que são impostos pela nobreza da ação e reconhecido patriotismo de S. Exa.

A autonomia dos municípios gaúchos, bem como a centralização de autoridade de seus prefeitos, dia a dia, desaparecem, num crescente desolador, ocasionando a queda do respeito dos administrados pelos administradores, trazendo a falta de harmonia e colaboração destes, uns com os outros, corpos sem cabeça nas localidades, tudo com evidentes prejuízos da ordem e do progresso municipal, gerando o boato desconcertante e o descontentamento público. ${ }^{44}$

Como se pode perceber, portanto, os casos de Santa Rosa e de Uruguaiana ilustram a divisão política regional que ainda persistia no Rio Grande do Sul durante o Estado Novo e também, na impossibilidade de harmonizar-se os interesses das diferentes alas da oligarquia gaúcha, a relativa independência que o interventor possuía em suas decisões no sentido de manter a ordem e a unidade do estado e do novo regime. De um lado, como vimos, havia uma certa autonomia do interventor em relação às oligarquias que, ape-

43 SILVA, Lúcia Silva e. Coronéis da fronteira: um olhar sobre a 'getulização' do Brasil. Porto Alegre, 1999, p. 45.

44 Arquivo Nacional. Fundo Gabinete Civil da Presidência da República, caixa 185, pacote RS. 
sar dos protestos, acabavam por subordinar-se às suas decisões; de outro, em relação ao próprio governo federal que, dadas as peculiaridades locais, geralmente referendava suas decisões sem tergiversar, como nos casos em tela.

Nesse sentido, as relações políticas entre os governos federal e estaduais durante o Estado Novo não devem ser vistas de forma linear e homogênea, mas numa perspectiva de complementaridade, em que os interventores desempenharam o importante papel de intermediários ou elos de ligação entre esses dois níveis de poder e os interesses nacionais e regionais.

Além dos interventores, porém, deve-se fazer referência também à atuação do DASP/CAE que desempenhou um papel igualmente significativo na implantação do projeto político estadonovista no Brasil, ainda que este Departamento tivesse sido criado como um órgão eminentemente técnico e administrativo, de caráter insulado e com o objetivo de implantar o universalismo de procedimentos na administração pública brasileira. ${ }^{45}$

Sendo assim, para que se possa melhor compreender a importância de sua atuação e suas relações com os governos federal e estaduais, e com as oligarquias regionais, deve-se lembrar que, ao contrário do discurso oficial, o insulamento burocrático não é um processo técnico e apolítico e, além do mais, como definiu Edson Nunes, a sociedade brasileira define-se pelo sicretismo entre a velha e a nova ordem.

No Rio Grande do Sul, tal como vimos ter ocorrido em relação à Comissão Mista e à composição do secretariado de governo gaúcho, os cargos de conselheiro do DASP/CAE foram divididos eqüitativamente entre os representantes dos diferentes grupos políticos regionais (FUG e PRL), também com vistas à conciliação de seus interesses e à manutenção do equilíbrio político regional.

Ao contrário, portanto, do que se poderia esperar de um órgão insulado, nenhum dos conselheiros do CAE-RS foi escolhido por sua formação técnica, mas, sobretudo, por suas vinculações políticas, senão vejamos: José Acioli Peixoto era ex-integrante do

45 O DASP foi criado pelo Decreto-lei no 579, de 30 de julho de 1938, que definia como suas atribuições, dentre outras, as seguintes: determinar, sob o ponto de vista da economia e da eficiência, mudanças a serem implantadas na administração pública; elaborar e fiscalizar a execução do orçamento da União; selecionar os candidatos aos cargos públicos federais por meio de concurso; padronizar o material para uso no serviço público.

No Rio Grande do Sul, o CAE foi regulamentado apenas pelo Decreto-lei $n^{\circ} 1202$, de 8 de abril de 1939, sendo definido como um órgão da administração do Estado, juntamente com o Interventor. 
Tribunal de Contas do Estado; Moysés Vellinho, membro do PRL, havia apoiado Getúlio Vargas em suas disputas com Flores da Cunha; Alberto Pasqualini, filiado ao PL, foi vereador de Porto Alegre entre 1935 e 1937 e, mais tarde, Secretário do Interior de Ernesto Dorneles, em 1943; Carlos Eurico Gomes era exSuperintendente de Saúde e Higiene do Distrito Federal; Camilo Teixeira Mércio tinha sido Deputado Federal entre 1936 e 1937; Gaston Englert, comerciante, havia exercido o cargo de Diretor do BANRISUL, em 1928, durante o governo de Getúlio Vargas no estado gaúcho; e Olivério de Deus Viana, era integrante do tradicional PRR.

Se, por um lado, a escolha desses conselheiros do DASP /CAE deu-se por critérios eminentemente políticos; por outro, em conseqüência, deve-se considerar que a atuação do Conselho Administrativo teve um caráter paradoxal, transitando entre o técnico e o político, o universalismo de procedimentos e o clientelismo. Podese dizer, desse modo, ao menos no caso gaúcho, que a atuação do CAE-RS deu-se em um sentido complementar à do interventor, e não apenas de fiscalização e controle, justificando com argumentos supostamente técnicos suas decisões políticas. A esse respeito, Vieira da Cunha afirma que o DASP desempenhou um papel relevante no jogo político do ditador, pois "era chamado a opinar sobre os mais diversos assuntos e o ditador, assim, conseguia fazer pesar nas decisões que mais lhe interessassem o prestígio de um órgão técnico". ${ }^{46}$

Nesse sentido, a título de exemplo, pode-se citar dois casos distintos da atuação do DASP/CAE no Rio Grande do Sul. Em relação aos municípios, um grande número de projetos era enviado diariamente ao CAE-RS, sobre as mais variadas temáticas, desde a criação de cargos, reajuste de vencimentos e aumento das verbas municipais, até a alteração do nome de um trecho de rua no município de Pelotas.

Ou seja, pode-se perceber claramente o alto grau de centralização administrativa que o CAE visava impor ao Estado, limitando o poder das elites locais e legitimando a ação do interventor que, desse modo, reforçava sua relativa autonomia de decisão em relação a estes grupos oligárquicos. Assim, segundo Dilan Camargo, "predominam entre as atividades do CAE as voltadas para os

46 VIEIRA DA CUNHA, Mário Wagner. O sistema administrativo brasileiro. Rio de Janeiro: Centro Brasileiro de Pesquisas Educacionais, 1963, p. 92. 
municípios, alcançando, quase sempre, cerca de $90 \%$ dos projetos e processos recebidos". 47

Já em relação à interventoria, ao contrário, a fiscalização exercida pelo Conselho Administrativo era muito menos rígida e, em alguns casos, inócua, apenas reafirmando com seus pareceres técnicos as decisões políticas já adotadas pelo interventor. Este foi o caso do projeto de reforma estatutária do instituto do arroz que, antes mesmo de ser enviado ao CAE, já havia obtido a aprovação do Presidente da República e, portanto, "tornava desnecessária e inócua qualquer intervenção daquele" Conselho. Mesmo assim, diz Camargo, "a Comissão não se negou a prestar sua 'colaboração', fazendo inúmeras observações". ${ }^{48}$ De igual maneira ocorreu a reformulação dos estatutos do instituto de carnes, que veio a ser apreciado e aprovado pelo CAE somente cerca de seis meses após sua efetiva implantação.

Em síntese, pode-se dizer que, ao contrário do que muitas vezes se supõe, as relações entre os diferentes níveis de poder durante o Estado Novo não podem ser vistas de forma homogênea e linear, como se a centralização e a nacionalização do regime tivessem sido realmente capazes de pôr fim às políticas regionais. De fato, houve uma limitação à autonomia das oligarquias estaduais, que foram submetidas ao poder de um interventor nomeado diretamente pelo Presidente da República. Porém, esta nunca foi uma condição absoluta nem suficiente para a manutenção da ordem estadonovista, que precisou negociar e cooptar permanentemente o apoio destas mesmas oligarquias.

Por este motivo, coube aos interventores a difícil missão de intermediar os interesses nacionais e regionais, constituindo-se no ponto de equilíbrio da estrutura de poder do Estado Novo. Já ao DASP/CAE coube a tarefa de modernizar e implantar o universalismo de procedimentos na administração pública brasileira e, muitas vezes, através de seus pareceres e argumentos "técnicos", acabou por legitimar as decisões políticas do interventor.

Pode-se dizer, portanto, que a organização e a legitimação do poder e de uma nova ordem política durante o Estado Novo foi uma tarefa das mais complexas e que, como bem disse Edson Nunes, esta nova ordem não eliminou completamente a velha, o que faz do Brasil uma sociedade sincrética.

47 CAMARGO, Dilan. Centralização e intervenção: padrão político e institucional do Estado Novo no Rio Grande do Sul - o Conselho Administrativo do Estado. Porto Alegre: UFRGS, 1995 (dissertação de mestrado), p. 119-120.

48 Ibid., p. 135. 